\title{
A RESISTANCE-COUPLED AMPLIFIER FOR MEASURING IONIZATION CURRENTS
}

\author{
By L. F. Curtiss
}

\section{ABSTRACT}

A description is given of a simple two-stage resistance-coupled vacuum-tube amplifier for use in measuring ionization currents down to the order of $10^{-13}$ ampere. Commercial dry-cell vacuum tubes are used. It can be calibrated and will retain its calibration over considerable periods within 1 percent. Where comparative measurements are required-for example, standardizing radium preparations-it is capable of a much higher accuracy. Readings are made on a pointer-type microammeter. The stability of the circuit indicates that a more sensitive instrument could be used if more feeble currents are to be measured. A description of interchangeable ionization chambers, suitable for use with such an amplifier, is given.

CONTENTS

I. Introduction

II. Description of the amplifier

Page

583

III. Mounting for ionization chambers

IV. Calibration of amplifier

V. Ionization chambers

VI. Acknowledgments

589

\section{INTRODUCTION}

Many devices have been developed to make use of the amplifying properties of vacuum tubes for the measurement of ionization currents. These vary in sensitivity from circuits using the FP-54 tube, ${ }^{1}$ capable of detecting currents of the order of $10^{-17}$ ampere to more insensitive arrangements intended for the measurement of heavier currents. Unfortunately such devices have not come into general use for measuring ionization currents produced by the radiations from radioactive substances. An important obstacle in the adoption of vacuum-tube amplifiers for the measurement of such currents, which range approximately from $10^{-10}$ to $10^{-14}$ amperes, has been the lack of suitable resistors for use in the input stage. Recently very satisfactory resistors of the order of $10^{10} \mathrm{ohms}$ have been made available commercially. This paper is intended to call attention to the great improvement in methods of measuring ionization currents which have thus been made available.

An amplifier, to be used advantageously for such purposes, must possess the following features: (1) direct instantaneous readings, eliminating timing of moving indicators by a stop watch or other timing device; (2) rugged, dead-beat indicating instrument, such as

I Dubridge, L. A., Phys. Rev., vol. 37, p. 392, 1931. 
microammeter or galvanometer of moderate sensitivity; (3) considerable range of sensitivity; and (4) reasonable accuracy in reproduction of readings from day to day. The writer has investigated the possibility of constructing such an amplifier and has found that a very simple two-stage resistance-coupled amplifier will accomplish the purpose. Such an arrangement can be made to give a current amplification of about $10^{6}$ without appreciable unsteadiness in the indicating instrument. An amplifier of this type has been used for $\alpha$-ray and $\beta$-ray measurements in the radium laboratory of the Bureau of Standards for about a year, and has met all ordinary requirements with a considerable saving in time. A description of the amplifier and some forms of ionization chambers which may be used with it is given in this paper.

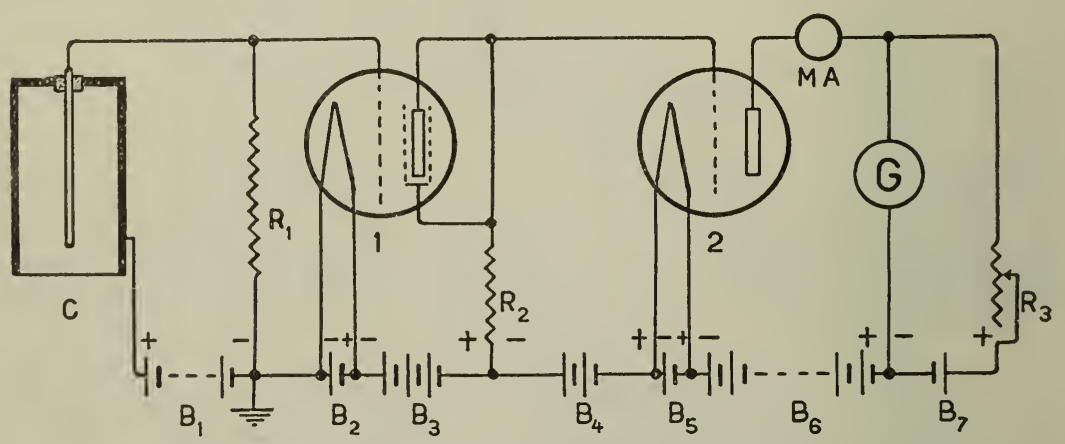

Figure 1.-Wiring diagram of amplifier.

$C=$ ionization chamber.

$B_{1}=1,000$ volts, $B_{2}=2$ volts, $B_{3}=6$ volts, $B_{4}=3$ volts.

$B_{5}=2$ volts, $B_{8}=90$ volts, $B_{7}=1.5$ volts.

$R_{1}=10^{10} \mathrm{ohms}, R_{2}=0.5$ megohm, $R_{3}=6-\mathrm{ohm}$ and $1,000 \mathrm{ohm}$ rheostats in series.

$M A=$ milliammeter.

$G=$ microammeter.

No. $1=$ ='32 vacuum tube. No. $2=$ ' 30 vacuum tube.

\section{DESCRIPTION OF THE AMPLIFIER}

Although the amplifier is of the ordinary direct-resistance-coupled type, it has been found that any marked departure from the arrangement finally adopted leads to trouble, so that a reasonably detailed description of the complete circuit is given. The chief source of difficulty seems to arise from ionization and creeping of electric charges in the first tube of the amplifier. Ionization of the residual gas in this tube can be avoided by keeping the plate voltage below about 6 volts, and the creeping of charges is also partially avoided by this precaution. The effect of this creeping can be eliminated sufficiently for all practical purposes by turning on the amplifier 2 or 3 hours before using it.

The amplifier consists of two stages, as shown in figure 1. A '32 type of radio tube is used in the first stage, 1, and a '30 type in the second stage, 2. These tubes are selected because they can be operated very conveniently and economically from dry cells which can be completely screened to reduce disturbances from outside. The screen-grid tube is used in the first stage since it has a control-grid lead brought out at the top which affords better insulation of the grid than is available in those tubes which have the control grid brought out 
at the base. The screen grid and plate of this tube are connected together.

The choice of voltages and resistors is fairly important for satisfactory operation, and those used by the writer are given in detail in the legend. $C$ represents the ionization chamber, the collecting rod of which is connected directly to the control grid of the first tube. $B_{1}$ is the battery which supplies a saturation roltage for the chamber. For complete steadiness it was found necessary to add a high resistance, $P_{1}$, across the input of the first stage. $B_{2}$ is the filament battery for the first tube. When using dry cells for this purpose, a rheostat and roltmeter for maintaining the proper filament roltage are desirable, although the sensitivity of the amplifier does not depend greatly on the filament temperature. $B_{3}$ supplies the plate potential for the first tube, and $P_{2}$ is the coupling resistor between the two stages. $B_{4}$ prorides the negatire bias for the second stage. $B_{5}$ is the filament battery for the second tube. Since this battery is about 10 or 12 rolts abore ground potential, it must be insulated to prerent short circuits. $B_{6}$ is the plate battery for the second tube and $B_{7}$ is a balancing battery for the circuit containing the meter $G$, used for actual measurements. The millimeter, $M A$, is used to indicate the plate current of the second tube and serves to show whether the amplifier is in operation.

Measurements of ionization' currents are made by means of the meter $G$, which may be a pointer type microammeter, in connection with the battery $B_{7}$ and the rheostat $R_{3}$. The operation consists in adjusting the rheostat $R_{3}$ until the reading of the meter $G$ is zero when the chamber $C$ is exposed to no ionizing agent. This meter will then indicate a current proportional to the current flowing in the ionization chamber when exposed to ionizing radiation.

For the most satisfactory operation all parts of the circuit should be electrostatically shielded. In addition, all connections to the grid of the first tube must be screened from the radiation to be measured. This presents some difficulty when, as frequently occurs, $\gamma$-radiation is to be measured. Since it is desirable to make the connection between the ionization chamber and grid as short as possible to aroid increasing the electrostatic capacity of the system, it is not conrenient to screen this connection from radiation. The problem can be solred br nullifying the effect of the ionization produced between this connection and its grounded shield. This can be done by filling this space with a solid insulating material, such as hard rubber or ceresin. Since this connection is grounded through the resistance $R_{1}$, of the order of $10^{10} \mathrm{ohms}$, a high degree of insulation is not required.

\section{MOUNTING FOR IONIZATION CHAMBERS}

The use of a screen grid tube makes it easy to provide a way of attaching ionization chambers to the amplifier so that the disturbance due to ionization around the grid lead is eliminated and also makes possible an arrangement so that different forms of ionization chambers can be substituted conreniently for the one in use at the moment. This greatly extends the usefulness of the equipment, since the same apparatus may be used to serve the purpose of an $\alpha$-ray, $\beta$-ray, or $\gamma$-ray electroscope by attaching the proper kind of ionization chamber. 
The method of mounting the tube and ionization chamber is shown in figure 2. As is shown, the screen grid tube is mounted in an inverted position, a short connection running down a shielded stem

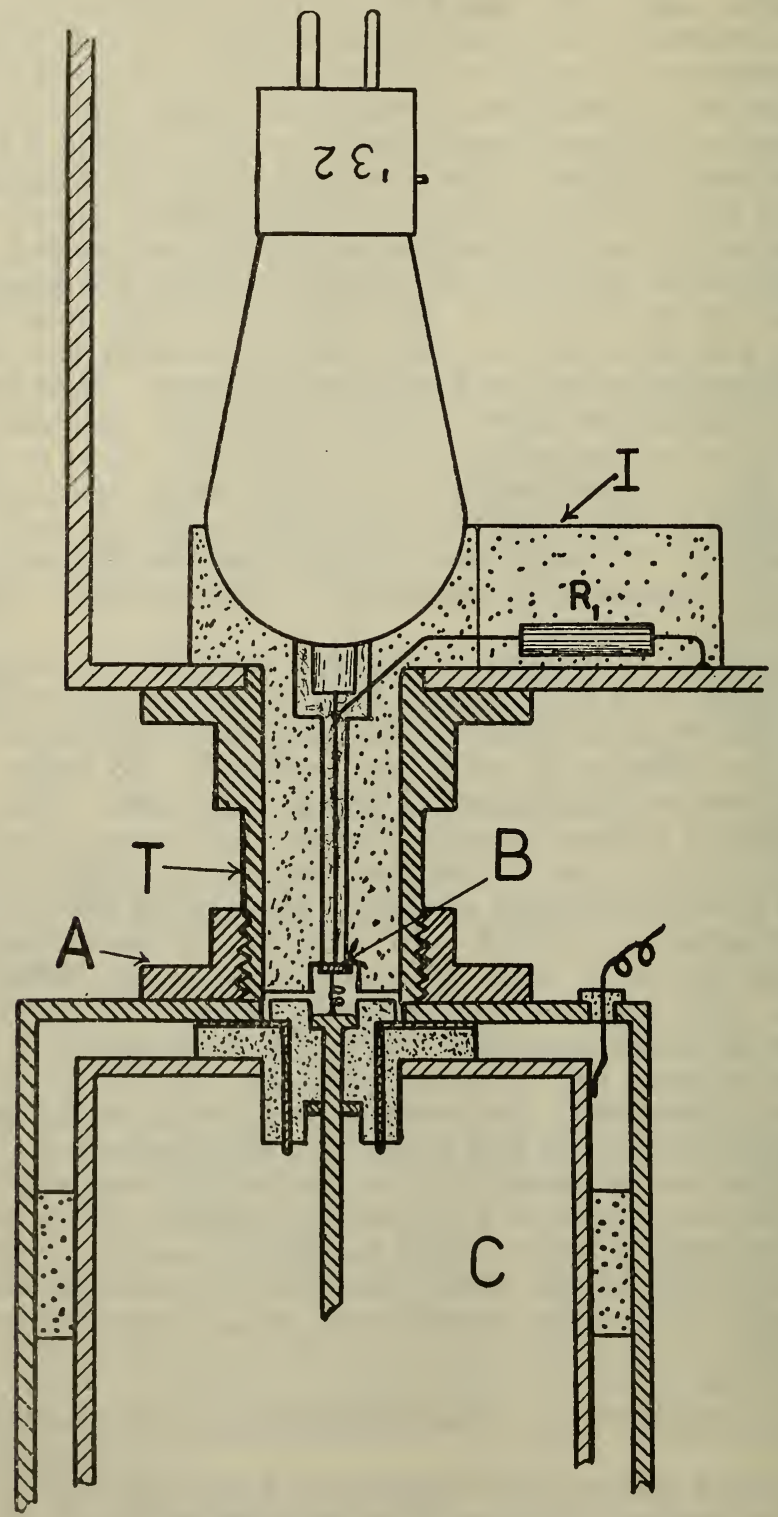

Figure 2.-Mounting for ionization chamber.

$T=$ connecting stem, $B=$ control button, $A=$ threaded collar, $C=$ ionization chamber, $R_{1}=10^{\mathrm{It}}$ ohms, $I=$ solid insulation.

to make connection with the ionization chamber $C$ below. This connection terminates in a metal button, $B$. The ionization chamber is supported by a threaded collar, $A$, which fits the threaded portion 
of the tube $T$, and when screwed into position a short spiral spring attached to the collector of the ionization chamber is pressed against this button, completing the connection. This permits the ready removal of the ionization chamber. The resistor $R_{1}$ is also embedded in the solid insulation $I$, to protect it from ionization.

\section{CALIBRATION OF AMPLIFIER}

The amplifier was calibrated indirectly by attaching an ionization chamber made according to the dimensions given by Irene Curie. ${ }^{2}$ Using this chamber, Curie states that one millicurie of radon in a thin-walled $\alpha$-ray bulb produces an ionization current of 0.064 e.s.u. when placed at $40 \mathrm{~cm}$ from the aluminum window. With this ionization chamber connected to the amplifier a deflection of approximately 10 microamperes per millicurie of radon was obtained at a distance of $40 \mathrm{~cm}$. Hence the amplifier yields a deflection of 1 microampere for an ionization current of about $2 \times 10^{-12}$ amperes under the conditions described. By using a more sensitive instrument in place of the microammeter-for example, a galvanometer with a sensitivity of the order $10^{-9}$ amperes per millimeter-it is possible to measure currents down to $10^{-14}$ amperes.

The calibration of the amplifier was made after it had been in continuous operation for about 4 hours. This was necessary because it was found that a slow decrease in sensitivity of the amplifier occurs during the first 2 hours of operation. This decrease is attributed to a slow accumulation of charge on the inner walls of the vacuum tubes which finally attains a saturation value. Careful tests have been made with the amplifier in continuous operation for periods up to 48 hours and no change in the sensitivity occurs after about 3 hours. Readings taken over these periods agreed with each other within 1 percent.

For purposes of checking the calibration conveniently over longer periods, a comparison was made between a thin-walled radon bulb and a radium standard. The radium preparation was exposed to the chamber without screening. The radiation was thus subjected only to the absorption occurring in the glass wall of the containing tube and in the salt of the preparation itself. For the radium preparation used for this comparison with an $\alpha$-ray bulb filled with radon, it was found that $1 \mathrm{mc}$ of radon was equivalent to $1.85 \mathrm{mg}$ of radium. Although this ratio depends upon the thickness of the aluminum window of the ionization chamber, the thickness of the glass walls of the tube containing the radium, and the distribution of salt in the radium preparation, as well as the wall thickness of the radon bulb, for conditions approximating those described here it gives roughly the amount of absorption of $\beta$-radiation to be expected in the salt and container for a radium preparation sealed in glass. The rapidity with which measurements may be made with this arrangement reduces the possibility of errors arising from fluctuations of temperature and barometric pressure. It also makes it very suitable for measurement of radiation from radioactive products of rapid decay, since continuous observation of the intensity of the radiation is possible.

'Curie, I., J. de Phys., vol. 22, p. 472, 1925. 


\section{IONIZATION CHAMBERS}

To indicate the variety of uses to which the amplifier may be put by means of interchangeable ionization chambers, four principal types of chambers are sketched in figure 3 . These chambers are all

fitted with a threaded collar, $A$, by which they may be attached to the amplifier. This collar is fastened to the outside grounded case which provides the electrical shielding for the chamber.

An $\alpha$-ray chamber is shown at $a$, constructed so that the active material may be introduced directly into the interior. The bottom

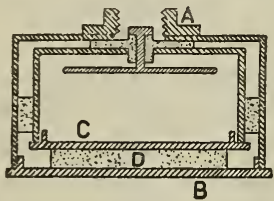

a

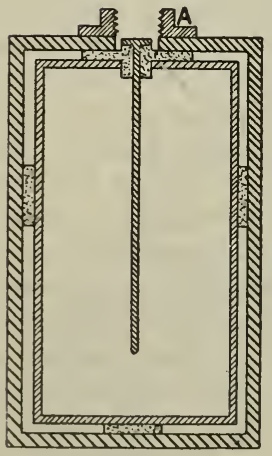

C

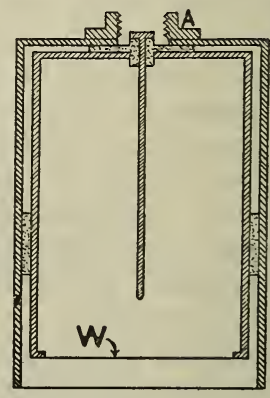

b

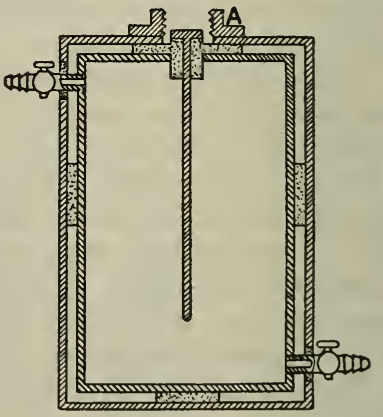

d

FigURE 3.-Types of ionization chambers.

$a$, a-ray chamber; $b, \beta$-ray chamber; $c, \gamma$-ray chamber; $d$, emanation chamber.

plate of this chamber is made of two parts separated by an insulating disk, $D$. The upper part is a metal tray, $C$, formed to close the lower end of the chamber when the lower metal disk, $B$, is screwed into the grounded case of the chamber. The active material is placed in the metal tray. A $\beta$-ray chamber is shown at $b$. The proportions are changed from that of the $\alpha$-ray chamber to take advantage of the longer ionizing paths of $\beta$ rays. The radiation is admitted through the thin aluminum window, $W$, which closes the lower end of the chamber. For measurement of $\gamma$ radiation a chamber surrounded by a lead shield, as shown at $c$, may be used. It is also possible to adapt this apparatus for the emanation measurements by the use of a chamber as sketched at $d$. 
The use of interchangeable chambers is of considerable advantage when working with material which may contaminate the chamber or in cases of accidental contamination. By providing a reserve chamber the contaminated chamber may be replaced at once when a sudden release of the contaminating material renders a chamber temporarily useless. Since the chambers may be so designed as to afford a possibility of thorough cleaning, those which have become contaminated may be renovated at leisure.

\section{ACKNOWLEDGMENTS}

The writer wishes to acknowledge the assistance of B. W. Brown and L. L. Stockman for help in constructing and calibrating an amplifier as described above. It is also a pleasure to acknowledge considerable help in the design of the amplifier from Dr. A. V. Astin and Dr. G. W. Gardiner.

Washington, February 16, 1933. 